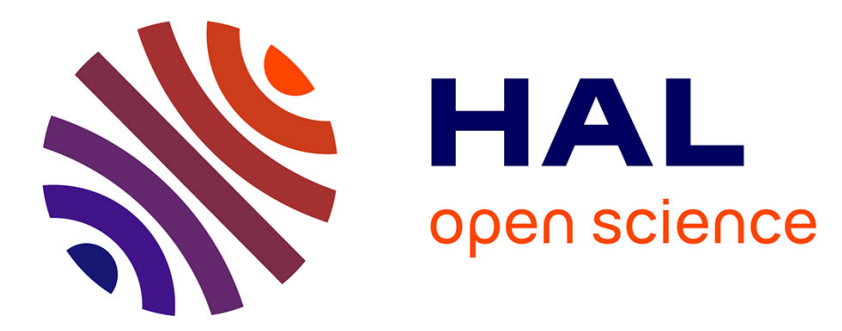

\title{
Infant learning of words in a typologically distant nonnative language
}

Hui Chen, Dahliane Labertonière, Hintat Cheung, Thierry Nazzi

\section{To cite this version:}

Hui Chen, Dahliane Labertonière, Hintat Cheung, Thierry Nazzi. Infant learning of words in a typologically distant nonnative language. Journal of Child Language, 2020, 10.1017/S0305000920000161 . hal-02565996

\section{HAL Id: hal-02565996 https://hal.science/hal-02565996}

Submitted on 6 May 2020

HAL is a multi-disciplinary open access archive for the deposit and dissemination of scientific research documents, whether they are published or not. The documents may come from teaching and research institutions in France or abroad, or from public or private research centers.
L'archive ouverte pluridisciplinaire HAL, est destinée au dépôt et à la diffusion de documents scientifiques de niveau recherche, publiés ou non, émanant des établissements d'enseignement et de recherche français ou étrangers, des laboratoires publics ou privés. 
Infant learning of words in a typologically distant nonnative language

\author{
Hui Chen ${ }^{1,2}$ \\ Dahliane Labertonière ${ }^{1,2}$ \\ Hintat Cheung ${ }^{3}$ \\ Thierry Nazzi ${ }^{1,2}$ \\ ${ }^{1}$ CNRS, Integrative Neuroscience and Cognition Center, Paris \\ ${ }^{2}$ Université Paris Descartes, Paris \\ ${ }^{3}$ The Education University of Hong Kong, Hong Kong
}

Chen, H., Labertonière, D., Cheung, H., \& Nazzi, T. (2020). Infant learning of words in a typologically distant nonnative language. Journal of Child Language. doi:10.1017/S0305000920000161

Acknowledgments

This project was supported by a joint ANR-RGC grant (ANR-15-CE28-0011 to T Nazzi, and RGC A-HKIEd801/15 to H Cheung) and by Labex EFL (ANR- 10- LABX- 0083) grant to T Nazzi. We thanks all infants and their parents, and Lionel Granjeon for statistical advice.

Address for Correspondence

Hui Chen, Integrative Neuroscience and Cognition Center, Université Paris Descartes, Sorbonne Paris Cité, Paris, France. Email: hui.chen@parisdescartes.fr 
2 word learning in a typologically distant language 
3 word learning in a typologically distant language

Abstract

Infants attune to their native language during the first two years of life, as attested by decreases in the processing of nonnative phonological sounds and reductions in the range of possible sounds accepted as labels for native words. The present study shows that French-learning infants aged 1;8 can learn new words in an unfamiliar language, Cantonese, after just 6 repetitions of each word. This shows that word learning in a nonnative language remains possible during the second year of life even in a nonnative language that is typologically very distinct from the native language.

Keywords: early language acquisition, word learning, language attunement, French, Cantonese 
Acquiring a language requires infants to learn, among other things, the sound patterns of their native language, its lexicon, its syntax. Infants are born with language-general abilities that allow them to start quickly learning the specific properties of their native language (or languages, in the case of bilingualism) based on the input they receive in their environment. For phonology, many studies show that infants start acquiring the vocalic and consonantal inventories of their native language (Kuhl, Williams, Lacerda, Stevens \& Lindblom, 1992; Polka \& Werker, 1994; Werker \& Tees, 1984; Best, McRoberts \& Sithole, 1988; among others), as well as its phonotactic regularities (Jusczyk, Luce \& Charles-Luce, 1994; Nazzi, Bertoncini \& Bijeljac-Babic, 2009) during the first year of life. Hence, lexical acquisition, which has already started by 5 months for a few highly frequent words (Tincoff \& Jusczyk, 1999, 2012; Bergelson \& Swingley, 2012), might be constrained early on by phonological acquisition. Next, we review what we know about the kind of labels infants accept as names for objects, evaluating whether an attunement process is also at stake at that level, and if so, whether it makes it more difficult for infants to subsequently learn words in a nonnative language, the issue explored in the present experiment. More specifically, we tested whether (French-learning) monolingual infants at age 1;8 can learn words in a language typologically very different from their native language that they had never heard before the experimental session (Cantonese).

Several studies have found that infants can accept a range of labels as names for objects, including non-linguistic labels such as gestures, noises, and pictograms in the first half of the second year of life, but stop doing so by age 1;8 and after (e.g., Namy, 2001; Namy \& Waxman, 1998; Woodward \& Hoyne, 1999). This reduction in the range of possible labels also extends to linguistic labels. This was found in studies teaching infants new (pseudo)words, in contexts that either suggest that the new words are part of the native language (e.g., by presenting familiar 
objects named by words familiar prior to teaching the new words, or by presenting the new words in sentence contexts), or do not provide any indication as to the language of the pseudowords, which would thus likely be interpreted as new words in the native language by monolingual infants. For example, English-learning infants could learn two new words that differed in both consonants and vowels, and in which the consonants were two different clicks from the N|uu language, independently of their vocabulary size at age 1;2, but only if they had low vocabularies at age 1;8 (May \& Werker, 2014; for converging findings using clicks from the Ndebele language, see Singh, 2018). This indicates that learning new words in the native language becomes more constrained as infants learn its phonological and lexical regularities, becoming more difficult when the labels include sounds (here click consonants) that do not exist as and cannot be assimilated to native sounds.

Such a pattern of reduction is also found for phonotactic constraints. This was first revealed in a study teaching English-learning infants aged 1;5-to-1;8 one phonotactically legal and one phonotactically illegal word in English (Graf Estes, Edwards \& Saffran, 2011). Infants could only learn the links for the phonotactically legal pseudowords. Moreover, the greater the difference between infants' performance for the two pseudowords, the larger their receptive vocabulary, suggesting a link between phonotactic knowledge and word learning. Difficulties at learning phonotactically illegal pseudowords were also found in English-learning 1-year-olds, who could learn new pseudowords in English and Japanese (when using pseudowords phonotactically legal in English, but phonetically different), but not in Czech (in which the words violated English phonotactics; MacKenzie, Curtin \& Graham, 2012). Moreover, French-learning infants aged 1;2 could better learn pseudowords with phonotactic structures that were more, compared to less, frequent in their native language (Gonzalez-Gomez, Poltrock \& Nazzi, 2013). 
Reduction was also found in the use of nonphonemic features in the native language. Dutch-learning infants could learn two new words pronounced in Mandarin and contrasting only on their tone (flat versus falling), a contrast not used lexically in non-tone Dutch, at ages 1;2-1;3, but not ages 1;5-1;6 (Liu \& Kager, 2018), although there is evidence that adults of non-tone languages can learn pairs of words only contrasted by a tone (e.g., Poltrock, Chen, Kwok, Cheung \& Nazzi, 2018). A similar reduction was found for vowel duration, which is used contrastively to learn new words at age 1;6 by Dutch- but not English-learning infants, vowel duration being lexically distinctive in Dutch but not in English (Dietrich, Swingley \& Werker, 2007). This suggests that the features used to represent words attune to those used in the native language.

While the above studies establish that the range of labels and features that infants are able to use when learning new words in their native language diminishes during the second year of life, they do not inform us of whether infants at the same age can still learn words in a situation in which they are taught new words in a clearly identifiable nonnative context. Such a maintained ability would be crucial for learning a new language. This would also inform us on whether this reduction of labels used in the native context pertains to difficulties in the processing of nonnative sounds or to infants stopping acceptance of these nonnative labels in a native context. The former explanation would predict that reduction would extend to word learning in a nonnative context, while it would not necessarily be the case for the latter explanation. The first study exploring this issue used an object manipulation task to teach French-learning monolinguals aged 1;8 pairs of novel pseudowords in either a nonnative language, English, or their native language, French (Bijeljac-Babic, Nassurally, Havy \& Nazzi, 2009). In every trial, the two pseudowords were made up of phonemes that existed in French or 
could assimilate to French phonemes, were phonotactically legal in French, and were phonetically contrasted (e.g., /nıl/ versus /kag/). Crucially, the pseudowords were presented in 6sentence passages spoken in either French or English by a bilingual speaker, so that infants could determine whether the pseudowords were new, unfamiliar words in their native language or in a nonnative language. Infants could learn in both conditions. This establishes some ability to learn words in a nonnative language at the age at which the range of possible labels used in the native context has started to reduce, providing preliminary evidence for the acceptability explanation.

A similar effect was found earlier in development, in French- and English-learning infants aged 1;2 tested on their ability to learn words presented in either French or English sentences (da Estrela \& Byers-Heinlein, 2016). When taught one native and one nonnative word, infants could learn both of them equally well, extending infants' ability to learn words in a nonnative language at a younger age. Yet, when taught two new words in the nonnative language, they could only learn the first word presented. This suggests some potential difficulties and limitations in learning nonnative words even in a sentence context.

The present study explores another factor that could impact infants' ability to learn words in a nonnative language, namely the linguistic distance between the native and nonnative languages. In both Bijeljac-Babic et al. (2009) and da Estrela and Byers-Heinlein (2016), the two languages contrasted (French and English) were typologically relatively similar (both being Indo-European languages), though infants should distinguish them based at least on rhythmic properties (e.g., Mehler, Jusczyk, Lambertz, Halsted, Bertoncini \& Amiel-Tison, 1988; Nazzi, Bertoncini \& Mehler, 1998). Would the ability to learn new words extend to more typologically distant nonnative languages? This question was motivated by recent studies coming from the bilingual literature starting to show effects of linguistic distance on word learning. 
In a study using an object manipulation task, bilingual infants aged 1;4 were tested on their ability to learn pairs of new French-like pseudowords, differing by one phonetic feature of their initial consonant (either voicing or place; Havy, Bouchon \& Nazzi, 2016). Two groups were tested: bilinguals exposed to languages (French and either Spanish, Italian or European Portuguese) in which the phonemes tested are realized relatively similarly ("similar contrast" group) and bilinguals exposed to languages (French and either English or German) in which the phonemes are acoustically more different (“different contrast" group) in terms of VOT values. Only the "similar contrast" bilinguals learned the new words. This establishes that phonetic distance between the two languages of bilingual infants influences their lexical acquisition.

A different effect of linguistic distance can also be deduced from another study in which infants aged 1;5 were taught two minimally different words, /bih/ -/dih/ (Fennell, ByersHeinlein, \& Werker, 2007). Infants were either English-learning monolinguals, English-French bilinguals or English-(Mandarin or Cantonese) Chinese bilinguals. These languages were chosen because the phonological contrast tested was aligned in English and Chinese but misaligned in English and French. Based on Havy et al. (2016), one might expect monolinguals and EnglishChinese bilinguals to succeed at learning the words, and English-French bilinguals to fail. Yet, both groups of bilinguals failed. Linguistic typology, English and French being Indo-European languages and Mandarin or Cantonese being Sino-Tibetan languages, might explain the failure of the English-Chinese bilinguals: while for the particular contrast tested English is closer to Chinese than to French, English is overall closer to French than to Chinese. The pattern of results by Fennell et al. (2007) would thus suggest that more general linguistic distance also impacts word learning performance. ${ }^{\mathrm{i}}$ 
The above findings suggest that increased linguistic distance diminishes bilingual infants' ability to learn new pairs of words in one of their native languages. Would linguistic distance effects extend to monolingual infants learning words in a nonnative language? To start tackling this question, we used the same task as Bijeljac-Babic et al. (2009), with only slight modifications (see Procedure), to explore whether French-learning infants aged 1;8 can also learn pseudowords in both French and typologically distant Cantonese. The nonnative pseudowords were made up of phonemes that could assimilate to French phonemes, followed French phonotactic constraints, and were phonetically very different. Given similar levels of learning of French and English pseudowords by French-learning infants aged 1;8 in BijeljacBabic et al. (2009), a negative effect of linguistic distance might result in failure at learning the Cantonese pseudowords, or lower performance levels compared to learning the French pseudowords. Since infants were tested on 4 different trials per language, we also explored potential changes in learning ability across time. To the best of our knowledge, this is the first study exploring the acquisition of Cantonese (pseudo)words by nonnative infants.

\section{Method}

\subsection{Participants}

As in Bijeljac-Babic et al. (2009), 24 monolingual French-learning infants were tested. They were aged 1;8 $(\mathrm{M}=1 ; 8 ; 20 ;$ range $=1 ; 7 ; 27-1 ; 10 ; 24 ; 9$ females, 15 males $)$. All infants were in good health, born full-term, heard French at least $80 \%$ of the time according to parental reports, and had no previous experience with a tonal language. Fourteen additional infants were tested but excluded from the analyses for the following reasons: not finishing the experiment 
10 word learning in a typologically distant language

(reliable data for less than 5 trials) (9), being fussy (3), systematically grabbing both objects (1) and parental interference (1).

\subsection{Stimuli}

The stimuli for the test trials consisted of 8 pairs of pseudowords and 8 triads of unfamiliar objects.

All pseudowords (see Table 1) followed the phonotactic rules of French and Cantonese, and could thus be pronounced in both languages. Within each pair, the pseudowords differed on every segment: vowel, consonant and -when pronounced in Cantonese- tone, to make them very distinct. We tried to find pseudowords that were not real words in both French and Cantonese. As this was impossible, we also selected some low frequency French (i.e., /sy/, /pel, /fa/, /lam/, $/ \mathrm{man} /, / \mathrm{pi} /, / \mathrm{k} \varepsilon /, \mathrm{t}^{\mathrm{t}} \mathrm{an} /$ ) and Cantonese (i.e., $/ \mathrm{kyn} 6 /$, /sy5/) words, making sure they were not listed in the French (Kern, 2003) or Cantonese (Tardiff \& Fetcher, 2008) versions of the MacArthur Communicative Development Inventory (MCDI).

In the French trials, the pseudowords were pronounced as French words embedded in French carrier sentences. In the Cantonese trials, they were pronounced as Cantonese words embedded in Cantonese sentences.

\section{TABLE 1 HERE}

The objects associated with the pseudowords were small unfamiliar objects for which infants had no names (see Bijeljac-Babic et al., 2009, for an example). In each triad, the objects maximally differed in shape, color and material (e.g. metal, plastic and wood).

The stimuli for the training trials were 1 apple and 2 different forks; and 1 horse and 2 different cars, and their labels. 


\subsection{Procedure}

Infants were tested individually in a quiet room for about $1 / 2$ hour. Each infant was seated on their caregiver's lap, across a table from two female experimenters, a French and a Cantonese native speaker. During the French trials, the Cantonese experimenter sat back and refrained from interacting with the infant, and vice versa for the Cantonese trials.

The procedure was a close adaptation of Bijeljac-Babic et al. (2009), taking into account the fact that two monolingual experimenters interacted with the infant, rather than a bilingual one. It began with a 'warm-up' phase, during which both experimenters showed the infant a plastic round toy that they would spin (a task impossible to reproduce at $1 ; 8$ ), so that infants would get used to taking and giving back objects.

The experimental phase consisted of 2 training trials in French followed by 2 test trials in French (to "teach" the infants the task in their native language), then 2 training trials in Cantonese followed by 4 test trials in Cantonese (to determine whether infants can learn in that nonnative language), and finally 2 last test trials in French (as a post-test to make sure infants were still in the task).

In the French (or Cantonese) training trials, the French (or Cantonese) experimenter first presented the infant with two familiar objects they should have a name for (fork/apple on one trial, and horse/car on the other). One of the objects was presented first and the infant was encouraged to play with it and give it back to the experimenter who then placed it on the table, at the infant's left, out of reach. The second object was then presented in a similar manner before being placed on the table to the infant's right. During the presentation of each object, the experimenter spoke in child-directed speech, named it 6 times (see Table 2), first holding the 
object in her hands, clearly looking at it, and always making sure the infant was looking at or focused on the object when it was named. Lastly, the experimenter presented a second exemplar of one of the first objects, named it 3 times, placed it in a large cup and asked the infant to put the other one in the cup.

\section{TABLE 2 HERE}

Test trials had the same structure, except that unfamiliar objects and pseudowords were used: the first two unfamiliar objects were named with two different pseudowords (e.g., tim/man) and the third one was named either like the first or the second object (tim or man). Infants' object choices thus allowed to evaluate learning.

The triads used for each language were counterbalanced across infants. The order of presentation of the test trials, the two objects which were named first, and which of these two objects related to the object used to evaluate learning were counterbalanced between infants. Moreover, the position of the target object on the table (leftmost vs. rightmost) was counterbalanced within infants; thus, half of the correct responses were on each side. Both experimenters had trained together to perform the task in a similar fashion.

\section{Results}

Infants correctly responded on all training trials right away, except for 5 trials $(5.2 \%$ of all training trials, 2 in French, 3 in Cantonese), in which they grabbed both objects. The trial was replayed and the infant provided with the correct answer.

For each test trial, infants were given a score of 1 when they chose the object with the requested name, and a score of 0 otherwise (see Figure 2 for data transformed into percentages, chance being 50\%). In the 4 French test trials, infants chose the object with the requested name 
2.42 times $(60.42 \%$ correct), which is significantly more than chance according to a Wilcoxon signed-ranks test, $Z=2.055, p=.040,2$-tailed. Eleven infants chose the correct object on more than half of the test trials, 4 on less than half of the test trials, and 9 chose equally often the correct and incorrect object, a tendency yet failing to differ significantly from chance, $\chi 2(2, \mathrm{~N}=$ 24) $=3.27, p=.195($ Table 3$)$.

\section{FIGURE 1 HERE}

In the 4 Cantonese test trials, the infants chose the correct object 2.50 times $(62.50 \%$ correct), which is significantly more than chance, $Z=2.828, p=.005$, 2-tailed. Thirteen infants chose the correct object on more than half of the test trials, 2 on less than half of the test trials, and 9 chose equally often the correct and incorrect object, which is significantly different from chance, $\chi 2(2, \mathrm{~N}=24)=8.07, \mathrm{p}=.018($ Table 3$)$.

Performance did not differ between the French and the Cantonese trials, $Z=.354, p=$ .724, 2-tailed.

To explore potential changes in performance suggested by apparent higher performance at the beginning of the Cantonese session, we compared block (first 2 or last 2 trials) performance within and across languages. The only significant difference was between the first (1.46 choices, $72.91 \%$ correct) and second Cantonese block (1.04 choices, $52.08 \%$ correct, related-sample Wilcoxon signed-ranks test, $Z=2.357, p=.018$, 2-tailed).

\section{TABLE 3 HERE}

\section{Discussion}

The present findings first confirm prior findings that, in an interactive object manipulation task that might be close to real world demands (presence of an experimenter, words 
presented in sentential context, objects labelled when infants are focused on them), Frenchlearning infants aged 1;8 can learn new words in French after just 6 repetitions of hearing an unfamiliar object named in sentential contexts by a pseudoword conforming to French phonology (e.g., Nazzi, 2005; Bijeljac-Babic et al., 2009). More crucially, they show that learning in such conditions can also happen when hearing stimuli and sentential contexts in a nonnative language, here Cantonese, extending a previous finding for French-learning infants being taught English words (Bijeljac-Babic et al., 2009). This confirms that at this age, they have highly efficient word learning routines, probably grounded in powerful social and pragmatic abilities, which can be used to learn words in their native language and in a nonnative language. In terms of the dynamics of the task, performance across the French trials did not differ between the beginning and the end of the experiment. This suggests that infants understood the task right away, and that the experiment was short enough so that they could still succeed at the end of the experiment. Yet, performance changed across the nonnative Cantonese trials: infants could learn the pseudowords in the first two Cantonese trials (and especially the first one), but then became less good. The reason for this pattern is unclear. Given the lack of change in performance for the French trials, one possibility is that processing Cantonese is more costly than processing native French, infants becoming tired or less attentive with time.

As discussed in the introduction, Cantonese had been chosen for the present study as it is typologically very distant from French, and definitely more so than English is to French, in phonological (e.g., presence of tones, presence of vowel length contrasts), morphological (e.g., quasi-absence of morphological inflections), syntactic (e.g., pro-drop language, topic-prominent language) and prosodic-pragmatic (e.g., extensive use of sentence-final-particles) properties (Gong, 1980; DeLancey, 2009). Therefore, the number of language-specific processing 
procedures learned by the infants at the age of testing that would be less efficient in processing that nonnative language (such as phoneme representation, word form segmentation, phrase grouping) is likely to be higher in the case of a distant compared to a close language. Yet, the present results establish that monolingual infants can learn new words in a typologically distant language. Together with Bijeljac-Babic et al. (2009), there is now evidence that under the conditions of the present experimental design, infants aged 1;8 can learn new words in a nonnative language in both a closer and a distant language. Level of performance was similar for both languages, with a mean performance of $60.42 \%$ for English, and $62.50 \%$ for Cantonese. This fails to establish an effect of linguistic distance on nonnative word learning, something to be further explored in a within-participant design using exactly the same tasks to teach infants words in both a closer and a more distant language. Does that mean that it is as easy to learn words in a nonnative language independently of linguistic distance? While this is a possibility, note that in both studies, certain constraints had been put on the creation of the stimuli. The English and Cantonese pseudowords were made up of phonemes that were likely to assimilate to French phonemes, and followed French phonotactics. Moreover, although the Cantonese sentences had a different syntax from French, with sentence-final particles, still the sentences were short, and the target words were emphasized with a small pause before the sentence-final particles. In doing so, we were able to show that infants can learn the words in both languages, but we might have artificially facilitated the learning of the words in Cantonese. Future studies should continue evaluating effects of linguistic distance given the dearth of experiments evaluating this effect coming from the literature on bilingual acquisition (Havy et al., 2016; Fennell et al., 2007). 
Regarding the reduction in the range of labels that infants accept as potential new words during development, we discussed evidence showing that the ability to learn new pseudowords in the native language is reduced around 1;8 if the pseudowords contain nonnative, non-assimilable phonemes, or do not follow the native phonotactic properties. The present study shows acquisition of nonnative words if their phonemes, although realized phonetically differently than in the native language, can be assimilated to native phonemes and follow native phonotactic properties. Future studies will have to evaluate whether success in learning the nonnative words depended on these properties. Alternatively, it is possible that when infants recognize they are learning words in a nonnative language, they do not apply those constraints of phoneme assimilation and phonotactic legality. This would further support a reduction in the range of possible nonnative labels for new words in the native language in terms of acceptability of these labels in native context, rather than processing difficulties.

In conclusion, the present study establishes that at age 1;8, infants can learn words in a typologically distant nonnative language. Since attunement to native phonological and lexical properties leads to reduction in the use of nonnative forms when learning words in native contexts, similar negative effects on the ability to accept these forms for word learning even in a clear nonnative context might have been expected. Here, we show that infants remain open to processing some nonnative forms in Cantonese, providing further evidence at the lexical level that infants remain open to learning a new language in spite of the emergence of a perceptual filter attuned to their native language (for convergent evidence at the phonological level at age 0;9, see Kuhl, Tsao \& Liu, 2003; Roseberry Lytle, Garcia-Sierra \& Kuhl, 2018). Given the importance of lexical learning for the acquisition of the native language by monolingual infants (e.g., Bates, Bretherton \& Snyder, 1988; Fernald, Perfors \& Marchman, 2006; Marchman \& 
Fernald, 2008), this has potentially important implications for early sequential bilingualism in establishing that basic language acquisition mechanisms are still available to learn in a nonnative language even after native language attunement has happened. How late this window of opportunity remains open is a question for the future, one that would intersect with issues of age of acquisition explored in the L2 domain (e.g., Birdsong, 2006), and of the continuity between simultaneous, early and late bilingualism (e.g., Grosjean, 1982; Luk \& Bialystok, 2013). 
18 word learning in a typologically distant language

\section{References}

Bates, E., Bretherton, I., \& Snyder, L. (1988). From first words to grammar: Individual differences and dissociable mechanisms. New York: Cambridge University Press.

Bergelson, E., \& Swingley, D. (2012). At 6-9 months, human infants know the meanings of many common nouns. Proceedings of the National Academy of Sciences, USA, 109, 32533258.

Best, C.T., McRoberts, G.W. \& Sithole, N.M. (1988). Examination of perceptual reorganization for nonnative speech contrasts: Zulu click discrimination by English-speaking adults and infants. Journal of Experimental Psychology: Human Perception and Performance, 14(3), $345-360$

Bijeljac-Babic, R., Nassurally, K., Havy, M., \& Nazzi, T. (2009). Infants can rapidly learn words in a foreign language. Infant Behavior and Development, 32, 476-480.

Birdsong, D. (2006). Age and second language acquisition and processing: A selective overview. Language Learning, 56, 9-49.

da Estrela, C. \& Byers-Heinlein, K. (2016). Vois-tu le kem? Do you see the bos? Foreign word learning at 14 months. Infancy, 21(4), 505-521.

Dietrich, C., Swingley, D., \& Werker, J.F. (2007). Native language governs interpretation of salient speech sound differences at 18 months. Proceedings of the National Academy of Sciences of the United States of America, 104 (41), 16027-16031.

DeLancey, S. (2009). "Sino-Tibetan languages," in The World's Major Languages, 2nd Edn, Ed B. Comrie (pp. 693-702). London; New York, NY: Routledge. 
19 word learning in a typologically distant language

Fennell, C.T. \& Byers-Heinlein, K. (2014). You sound like Mommy: Bilingual and monolingual infants learn words best from speakers typical of their language environments. International Journal of Behavioral Development, 38, 309-316.

Fennell, C.T., Byers-Heinlein, K., \& Werker, J. F. (2007). Using speech sounds to guide word learning: The case of bilingual infants. Child Development, 78, 1510-1525. doi:10.1111/j.1467-8624.2007. 01080.x

Fernald, A., Perfors, A., \& Marchman, V.A. (2006). Picking up speed in understanding: speech processing efficiency and vocabulary growth across the 2nd year. Developmental Psychology, 42(1), 98-116.

Gong, H. C. (1980). A comparative study of the chinese, tibetan, and burmese vowel systems. Bull. Instit. Hist. Philol. Acad. Sin. 51, 455-489.

Gonzalez-Gomez, N., Poltrock, S., \& Nazzi, T. (2013). A "bat" is easier to learn than a "tab": Effects of relative phonotactic frequency on infant word learning. PLOS ONE, 8:e59601. doi: 10.1371/journal.pone.0059601

Graf Estes, K., Edwards, J., \& Saffran, J.R. (2011). Phonotactic constraints on infant word learning. Infancy, 16, 180-197.

Grosjean, F. (1982). Life with Two Languages. Cambridge, MA: Harvard University Press.

Havy, M., Bouchon, C. \& Nazzi, T. (2016). Phonetic processing when learning words: The case of bilingual infants. International Journal of Behavioral Development, 40(1), 41-52. doi:10.1177/0165025415570646

Jusczyk, P. W., Luce, P. A., \& Charles-Luce, J. (1994). Infants' sensibility to phonotactic patterns in the native language. Journal of Memory and Language, 33, 630-645. 
Kern, S. (2003). Le compte-rendu parental au service de l'évaluation de la production lexicale des enfants français entre 16 et 30 mois. (The parental questionnaire as a tool to evaluate lexical production by French infants between 16 and 30 months of age). Glossa, 85, 48-62.

Kuhl, P.K., Williams, K.A., Lacerda, F., Stevens, K.N., \& Lindblom, B. (1992). Linguistic experience alters phonetic perception in infants by 6 months of age. Science, 255, 606608.

Kuhl, P.K., Tsao, F.M., \& Liu, H.M. (2003). Foreign-language experience in infancy: Effects of short-term exposure and social interaction on phonetic learning. Proceedings of the National Academy of Sciences of the United States of America, 100, 9096-9101.

Liu, L. \& Kager, R. (2018). Monolingual and bilingual infants' ability to use non-native tone for word learning deteriorates by the second year after birth. Frontiers in Psychology, 9:117.

Luk, G., \& Bialystok, E. (2013). Bilingualism is not a categorical variable: Interaction between language proficiency and usage. Journal of Cognitive Psychology, 25, 605-621.

MacKenzie, H., Curtin, S., \& Graham, S.A. (2012). 12-month-olds' phonotactic knowledge guides their word-object mappings. Child Development, 83, 1129-1136.

Marchman, V.A. \& Fernald, A. (2008). Speed of word recognition and vocabulary knowledge in infancy predict cognitive and language outcomes in later childhood. Developmental Science, 11, F9-F16. DOI: 10.1111/j.1467-7687.2008.00671.x

May, L. \& Werker, J.F. (2014). Can a click be a word?: Infants' learning of non-native words. Infancy, 19(3), 281-300.

Mehler, J., Jusczyk, E W., Lambertz, G., Halsted, N., Bertoncini, J., \& Amiel-Tison, C. (1988). A precursor of language acquisition in young infants. Cognition, 29, 143-178. 
21 word learning in a typologically distant language

Namy, L.L. (2001). What's in a name when it isn't a word? 17-month-olds' mapping of nonverbal symbols to object categories. Infancy, 2(1), 73-86.

Namy, L.L., \& Waxman, S.R. (1998). Words and Gestures: Infants' interpretations of different forms of symbolic reference. Child Development, 69, 295-308.

Nazzi, T. (2005). Use of phonetic specificity during the acquisition of new words: differences between consonants and vowels. Cognition, 98,13-30.

Nazzi, T., Bertoncini, J. \& Bijeljac-Babic, R. (2009). A perceptual equivalent of the labialcoronal effect in the first year of life. Journal of the Acoustical Society of America, 126, 1440-1446. doi:10.1121/1.3158931

Nazzi, T., Bertoncini, J., \& Mehler, J. (1998). Language discrimination by newborns: Toward an understanding of the role of rhythm. Journal of Experimental Psychology: Human Perception and Performance, 24(3), 756-766. doi:10.1037/0096-1523.24.3.756

Polka, L., \& Werker, J. F. (1994). Developmental changes in perception of non-native vowel contrasts. Journal of Experimental Psychology: Human Perception and Performance, 20, $421-435$.

Poltrock, S., Chen, H., Kwok, C., Cheung, H. \& Nazzi, T. (2018). Adult learning of novel words in a non-native language: Consonants, vowels, and tones. Frontiers in Psychology, 9:1211. doi: 10.3389/fpsyg.2018.01211

Roseberry Lytle, S., Garcia-Sierra, A. \& Kuhl, P.K. (2018). Two are better than one: Infant language learning from video improves in the presence of peers. Proceedings from the National Academy of Science, 115, 9859-9866. 
Singh, L. (2018). Bilingual infants demonstrate advantages in learning words in a third language. Child Development, 89(4), e397-e413.

Tardiff, T., \& Fetcher, P. (2008). Chinese Communicative Development Inventories: User's guide and manual (Putonghua and Cantonese versions). Beijing, China: Peking University Medical Press.

Tincoff, R. \& Jusczyk, P.W. (1999). Some beginnings of word comprehension in 6-month-olds. Psychological Science, 10, 172-175.

Tincoff, R. \& Jusczyk, P.W. (2012). Six-month-olds comprehend words that refer to parts of the body. Infancy, 17, 432-444.

Werker, J.F. \& Tees, R.C. (1984). Cross-language speech perception: Evidence for perceptual reorganization during the first year of life. Infant Behavior and Development, 4(1), 49-63. doi:10.1016/S0163-6383(84)80022-3

Woodward, A.L. \& Hoyne, K. (1999). Infants' learning about words and sounds in relation to objects. Child Development, 70, 65-77. 
Table 1. Stimuli used in the experiment.

\begin{tabular}{lll}
\hline pair1 & to3 & fa4 \\
pair2 & kyn6 & lam1 \\
pair3 & sy5 & p 2 2 \\
pair4 & tim1 & man2 \\
pair5 & ko6 & pi3 \\
pair6 & sim1 & kun6 \\
pair7 & ti3 & ke6 \\
pair8 & $\mathrm{t}^{\mathrm{h}}$ an5 & k ${ }^{\mathrm{h}}$ em3 \\
\hline Numbers adjoined to the pseudowords correspond to Cantonese tones [T1 (High \\
Level 55), T2 (High Rising 25), T3 (Mid Level 33), T4 (Low Falling 21), T5 (Low \\
Rising 23), T6 (Low Level 22)]
\end{tabular}


Table 2. Sentences used to introduce the words and test learning.

\begin{tabular}{|c|c|c|c|}
\hline Cantonese & Gloss & English translation & French \\
\hline 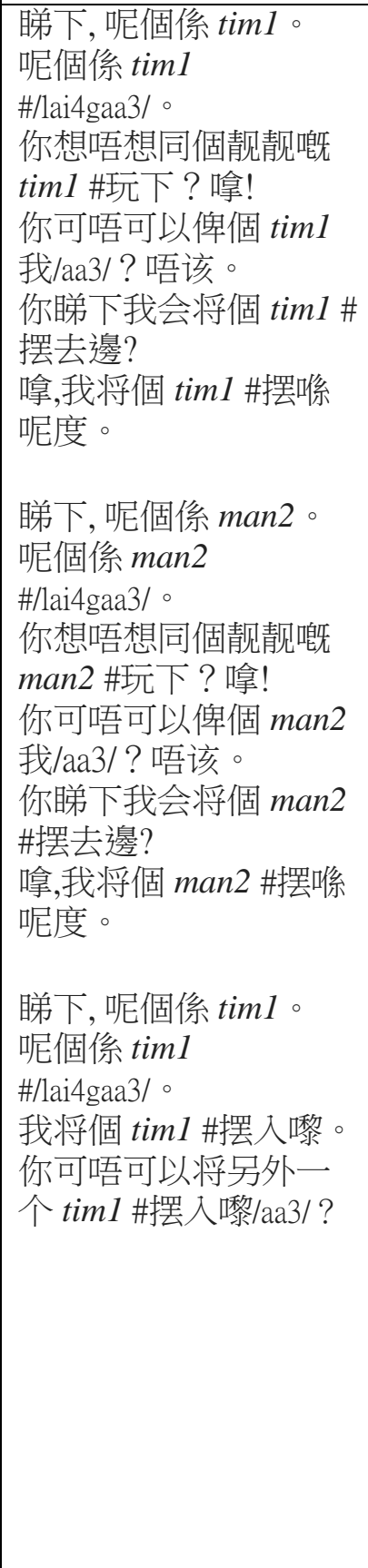 & $\begin{array}{l}\text { look, this is timl } \\
\text { this is } t i m 1 / \text { sfp/* } \\
\text { you want-not-want } \\
\text { with the pretty timl } \\
\text { play? give** } \\
\text { you can-not-can give } \\
\text { the timl me /sfp/? } \\
\text { thanks } \\
\text { you see I will put the } \\
\text { timl put to where? } \\
\text { see, I put the timl } \\
\text { put here. }\end{array}$ & $\begin{array}{l}\text { Look, this is a man2. } \\
\text { This is a man2. } \\
\text { Do you want to play } \\
\text { with the pretty man } 2 \text { ? } \\
\text { Take it! } \\
\text { Can you give me the } \\
\text { man2? Thanks. } \\
\text { Do you see where I } \\
\text { will put the man2? } \\
\text { I put the man2 here. }\end{array}$ & $\begin{array}{l}\text { Regarde! Un tim. } \\
\text { C'est un tim. } \\
\text { Tu veux jouer avec ce } \\
\text { tim? Tiens ! } \\
\text { Tu veux me donner le } \\
\text { tim? Merci. } \\
\text { Regarde où je mets ce } \\
\text { tim. } \\
\text { Je mets le tim, ici. }\end{array}$ \\
\hline
\end{tabular}

*/sfp/: sentence final particle;

** 嗱: a special interjection in Cantonese, used when giving or showing thing(s) to others. 
Table 3. Distribution of infants according to their performance (chance level $=2$ )

\begin{tabular}{llllll}
\hline Performance level & 0 & 1 & 2 & 3 & 4
\end{tabular}

$\begin{array}{llllll}\text { \# infants (French trials) } & 0 & 4 & 9 & 8 & 3 \\ \text { \# infants (Cantonese trials) } & 0 & 2 & 9 & 12 & 1\end{array}$




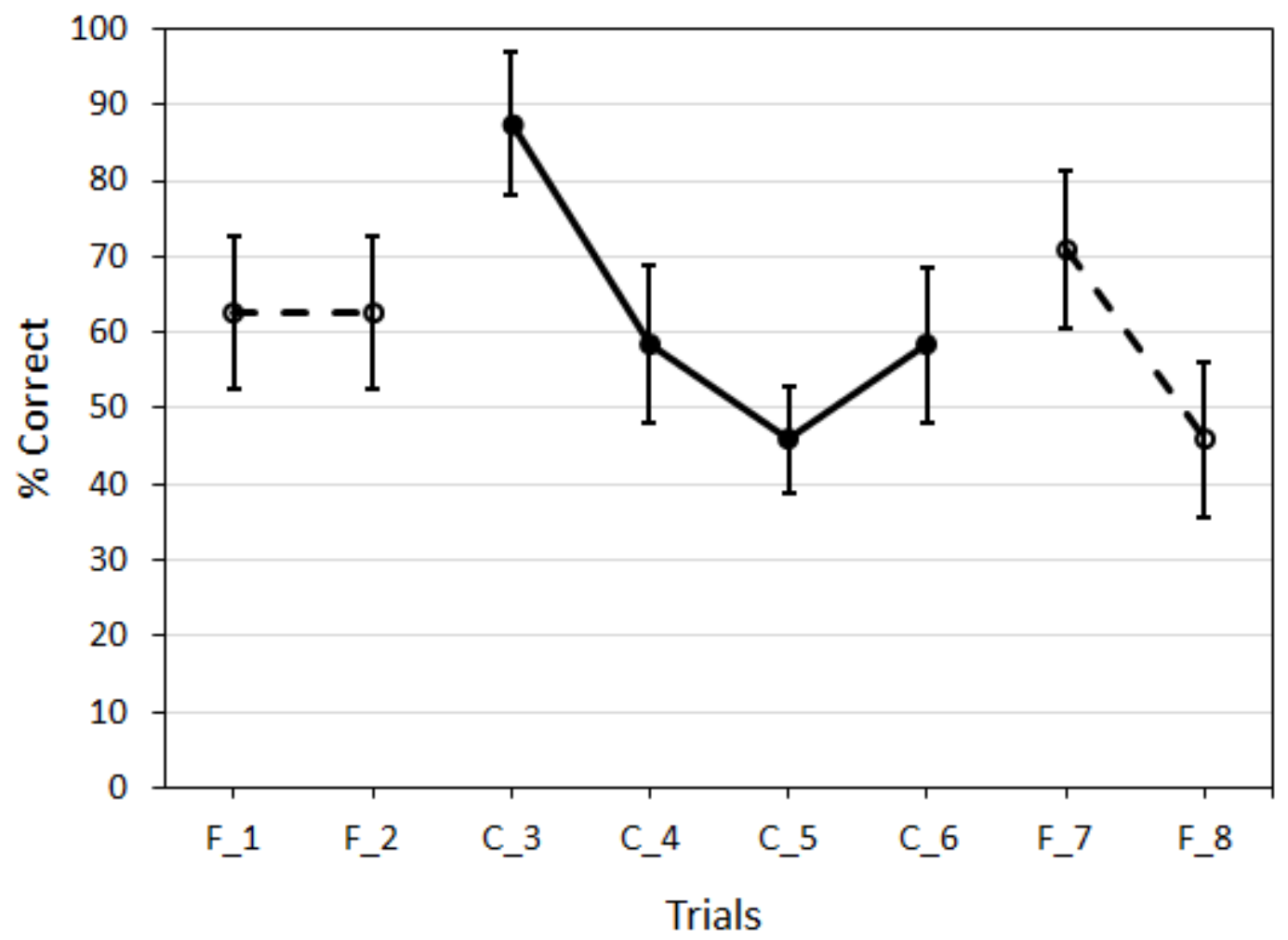

Figure 1. Mean correct responses in percentage (and S.E.) for the four trials in the nonnative language (trials 3-5) and the four trials in the native language (trials 1-2, and 7-8). 
${ }^{\mathrm{i}}$ A later study using stimuli produced by either a monolingual or a bilingual speaker, and testing English monolingual or English-French bilingual infants aged 1;7, revealed success in both populations when being presented with stimuli matching their linguistic environment (Fennell \& Byers-Heinlein, 2014). However, because there is no equivalent study with English-Chinese bilinguals, these new findings are not relevant for evaluating effects of linguistic distance. 